\title{
PLANEJAMENTO EDUCACIONAL NA EDUCAÇÃO A DISTÂNCIA
}

\author{
GOIÂNIA/GO AGOSTO/2018
}

\author{
Sarah Vieira Matos - SENAI GO - sarahmatos@sistemafieg.org.br \\ Tipo: Relato de Experiência Inovadora (EI) \\ Categoria: Métodos e Tecnologias \\ Setor Educacional: EDUCAÇÃO MÉDIA E TECNOLÓGICA
}

\begin{abstract}
RESUMO
O presente artigo tem como foco o processo de elaboração e continuidade do Planejamento Educacional nos Cursos a distância desenvolvidos pelo Núcleo Integrado de Educação a Distância SESI/SENAI Goiás e como a prática pedagógica associada a técnica implementada pelos cursos podem proporcionar ao aluno uma experiência inovadora. O planejamento educacional ocorre na busca de estratégias e intenções de ensinos que garantam a permanência, aproveitamento e qualidade dos cursos, promovendo uma relação de ensino e aprendizagem atualizada com o novo modelo almejado da Indústria 4.0, e na perspectiva de satisfação e inserção dos alunos no mercado de trabalho, assim como na sua formação humana.
\end{abstract}

Palavras-chave: Educação a Distância - EaD; Mediação, Tutoria; Metodologia. 


\section{Introdução}

Devido aos avanços tecnológicos ocorridos nos últimos anos, observa-se constantes mudanças na vida social, econômica e cultural dos sujeitos na sociedade. A expansão de acesso à informação e comunicação que as tecnologias proporcionam tem afetado diretamente o processo de ensino e aprendizagem, impulsionando cada dia mais a metodologia de educação a distância.

Assumindo a postura de que a tecnologia não é capaz de promover educação por si só e negando o modelo de educação baseado apenas na transmissão de conhecimento, o SESI SENAI de Goiás atua com a finalidade de formar profissionais qualificados para atuarem nos mais diversos setores, contribuindo, assim, para elevar a produtividade industrial, desenvolvimento social e consequentemente a economia do nosso Estado. Nessa perspectiva, a Educação a Distância no SESI SENAI de Goiás vem se concretizando como forma de democratização de um ensino de qualidade e de maneira flexível em relação ao tempo e espaço.

Segundo a LEGISLAÇÃO FEDERAL- Decreto ํo 2494, de 10 de Fevereiro de 1998 regulamenta o artigo 80 da LDB (Lei n. ⒐394/96), educação a distância é

\footnotetext{
Uma forma de ensino que possibilita a autoaprendizagem, com a mediação de recursos didáticos sistematicamente organizados, apresentados em diferentes suportes de informação, utilizados isoladamente ou combinados e veiculados pelos diversos meios de comunicação. (BRASIL,1998)
}

Com isso, o planejamento educacional na educação a distância dos cursos ocorre muito antes de seu início, assim como em todo seu decorrer e após o seu término. Visto que as novas tecnologias se desenvolvem a cada dia, e é necessário a realização de cursos que atendam a essas novas demandas.

O ato de planejar, como todos os outros atos humanos, implica escolha e, por isso, está assentado numa opção axiológica. É uma "atividade-meio", que subsidia o ser humano no encaminhamento de suas ações e na obtenção de resultados desejados, portanto, orientada por um fim. (LUCKESI, 2008, p.106)

\section{Objetivos}

Segundo Luckesi (2008, p. 105) "O ato de planejar é a atividade intencional pela qual se projetam fins e se estabelecem meios para atingi-los. “

O planejamento educacional na educação a distância do SESI/SENAI tem como centralização, verificar o objetivo do ensino, na perspectiva de análise de como seria o discente que queremos formar ao final do curso, realizar os planejamentos de execução, elaboração e atualização dos cursos, alinhar os planos e documentos contidos nos cursos e validar os mesmos por meio de uma equipe pedagógica e técnica, acompanhar e auxiliar os docentes na construção dos documentos necessários para a realização e 
andamento do curso, assim como sua didática com o aluno no Ambiente Virtual de Aprendizagem, avaliar como estamos meio a modernização atual, e atendimento a demanda da industrialização 4.0, por fim analisar os resultados obtidos ao final do curso, e planejar ações que visem melhoria desses processos.

No presente artigo, será apresentado como se dá esse processo de planejamento dos cursos.

\section{Referencial teórico}

O planejamento educacional pode ser definido como " o processo de abordagem racional e científica dos problemas de educação, incluindo definição de prioridades e levando em conta a relação entre os diversos níveis do contexto educacional" (LUCKESI,2008).

Sendo assim, faz-se necessário uma comunhão de valores que permitam uma base axiológica e pedagógica constituída de uma adoção de condutas e procedimentos que corroborem em um desenvolvimento curricular que estimulem à criatividade, à iniciativa, à autonomia, ao senso crítico com responsabilidade e à expressão de diferentes capacidades.

Segundo Luckesi (2008), “Nossa ação fundamenta-se em juízos de valor sobre o mundo que nos cerca: a natureza, a sociedade em que vivemos, o futuro a ser vivido, as relações com as pessoas, as vivências. ".Corroborando com esse pensamento, Zitkoski (2010) baseado em Freire afirma que " frente aos problemas que a realidade atual nos apresenta, precisamos impulsionar novos momentos de ação para que possamos atingir outros níveis de humanização do mundo, da sociedade e da cultura. "Visto isto, a Educação a distância já está um passo à frente do ensino tradicional, de forma a atender os sujeitos com ensino flexível em relação ao tempo e espaço. Importante ressaltar a agilidade em atender os desafios atuais de educação, devido às mudanças no contexto social e educacional advindas da $4^{\circ}$ revolução industrial, segundo uma matéria da BBC a $4^{\text {a }}$ revolução pode ser compreendida

\footnotetext{
Agora, a quarta mudança traz consigo uma tendência à automatização total das fábricas - seu nome vem, na verdade, de um projeto de estratégia de alta tecnologia do governo da Alemanha, trabalhado desde 2013 para levar sua produção a uma total independência da obra humana. A automatização acontece através de sistemas ciberfísicos, que foram possíveis graças à internet das coisas e à computação na nuvem. Os sistemas ciberfísicos, que combinam máquinas com processos digitais, são capazes de tomar decisões descentralizadas e de cooperar entre eles e com humanos - mediante a internet das coisas. (PERASSO, 2016)
}

Nessa perspectiva, procuramos atender e formar sujeitos que desenvolvam esse trabalho, "Para ser válida, a educação deve considerar a vocação ontológica do homem - vocação de ser sujeito - e as condições em que ele vive: em tal lugar exato, em tal momento, em tal contexto. " (FREIRE,1979). 
Os docentes envolvidos nesse processo possuem conhecimento não somente técnico, são formados por uma educação multidimensional, que abrange áreas técnicas, pedagógicas e da sociedade em geral, mantendo sempre uma educação continuada, para oferecer um ensino atual e de qualidade.

O sistema de EaD adotado pelo SESI SENAI em Goiás conta com uma estrutura organizacional composta de equipe técnica multidisciplinar. A equipe responsável pela gestão e execução dos cursos na modalidade EaD no NIEaD (Núcleo Integrado de Educação a Distância) é responsável por articular, propor, problematizar, mediar, operacionalizar e acompanhar os processos pedagógicos e administrativos dos cursos. Faz-se necessário então uma prática pedagógica com princípios facilitadores, contendo uma organização curricular flexível, fazendo uma referência ao contexto de trabalho e das empresas, às demandas da sociedade e às necessidades dos alunos, por um tratamento interdisciplinar de conhecimentos e práticas profissionais.

Planejamento curricular é uma tarefa multidisciplinar que tem por objeto a organização de um sistema de relações lógicas e psicológicas dentro de um ou vários campos de conhecimento, de tal modo que se favoreça ao máximo o processo ensino-aprendizagem. (LUCKESI,2008)

De acordo com Alves (2011, p. 85), segundo Dohmem em 1967, conceitua a educação a distância como uma forma de estudo sistematicamente organizada de auto estudo, assim, o estudo do material apresentado é acompanhado e supervisionado por uma equipe de professores, isto é possível graças as tecnologias de comunicação que ultrapassam as longas distâncias.

As ações de educação a distância, desenvolvidas no SESI/SENAI de Goiás, são amparadas pela Lei de Diretrizes e Bases da Educação Nacional, LDB 9.394/96, que no artigo 80 apresenta educação a distância como uma modalidade válida em todos os níveis de ensino. Assim, a educação a distância no SESI SENAI de Goiás é realizada nas modalidades de Educação de Jovens e Adultos, Educação Continuada, Educação Profissional, Aperfeiçoamento Profissional, Qualificação Profissional, Habilitação Técnica e Especialização. Em seu portfólio há diversos cursos em diversas áreas, tais como: Educação, Gestão, Automotiva, Construção Civil, Eletroeletrônica, Informática, Logística, Meio Ambiente, Segurança no Trabalho, Tecnologia da Informação e Comunicação, Automação e Telecomunicação.

A prática pedagógica que norteia a educação a distância SESI/SENAI apoia a aprendizagem significativa, a ideia de que o desenvolvimento de competências supõe uma aprendizagem que permita ao aluno lidar com o novo e crescer em autonomia, nessa perspectiva o aluno está como sujeito da relação, ou protagonista do processo de ensino aprendizagem e o docente como o responsável por mediar o processo de aprendizagem do aluno, atribuindo significado à teoria e às práticas desenvolvidas, fazendo a integração. 
Para Vygotsky (1989), a mediação consiste na zona de desenvolvimento proximal do aluno, ou seja, o aluno já possui um conhecimento que ele chama de desenvolvimento real, que observando suas capacidades, se estabelece um provável desenvolvimento potencial, o que o aluno é capaz de alcançar, com isso, através da mediação do professor na aprendizagem é chamada de zona de desenvolvimento proximal.

Com base nisso, é feito um planejamento educacional e curricular do que será trabalhado em cada curso e com determinados alunos. A mediação pelos tutores se sustentam nas situações desafiadoras, chamamos de Situação de Aprendizagem - SAP, onde as perguntas devem ajudar e decodificar informações, definição de problemas, analisar contextos, realizar inferências, comparar, levantar hipóteses e realizar uma correlação entre a situação apresentada e as já vivenciadas, entrelaçando a prática e a teoria, para que os próprios sujeitos possam transformar informações em conhecimentos. Segundo Freire (1985), a preocupação pela pergunta não deve ficar apenas no âmbito de uma pergunta sem objetivo, deve sempre ligar as perguntas e 0 resultado delas as ações praticadas pelo sujeito.

Sendo assim, os conteúdos dos cursos são desenvolvidos pelo Departamento Nacional, que observa as demandas dos núcleos regionais e juntamente com uma equipe técnica e pedagógica desenvolve o material de Plano de Curso e Plano de ensino a ser utilizado em cada curso ofertado. Porém, as unidades ofertantes dos cursos possuem autonomia para realizar adaptação nas situações de aprendizagens a serem desenvolvidas, como trabalhar com determinado aluno, no planejamento das aulas e demais ações desenvolvidas.

Para que se ensino algo, o conteúdo a ser trabalhado precisa ter significado ao aluno, é necessário que se atribua características e atributos de acordo com a particularidade dos sujeitos, sociais, históricos, interdisciplinares que estão além dos conceitos.

Outro ponto relevante na mediação é a transcendência, deve se pensar ao mediar uma disciplina, o que professor vai construir nesse espaço, de sala de aula ou ambiente virtual de aprendizagem, o aluno vai conseguir transcender esse espaço, tem como objetivo promover a aquisição de princípios, conceitos e estratégias que possam ser generalizados para outras situações e outras disciplinas. Assim, despertando o interesse do aluno, gerando significado.

Um fator importante para que o aluno entre no curso e permaneça, é a mediação do sentimento de competência, onde o professor mediador é responsável em fazer o aluno se sentir competente, incentivar o sentimento de competência. Interagir com o aluno de tal forma com que ele se sinta engajado e motivado. Por meio dos feedbacks, mensagens, ligações, fóruns o professor promove essa interação com os sujeitos. Atribuir valor e significado ao sucesso do aluno, apresentando o seu desempenho, atribuindo valor social ao comportamento eficiente. 


\section{Procedimentos metodológicos}

Para que esses processos ocorram de forma eficaz, a equipe técnica e pedagógica do NIEAD se baseia em documentos e cronogramas norteadores. Após a solicitação de um determinado curso ao Departamento Nacional que elaboram o conteúdo do curso, é enviado um documento de Plano de Curso, que é ajustado para cada regionalidade, onde é mencionado a carga horária do curso, a justificativa, qual o objetivo geral e específico, quais são os requisitos de acesso, a organização curricular, qual o perfil profissional após a conclusão do curso, a metodologia utilizada para alcançar os objetivos, critérios de aproveitamento de conhecimentos e experiências anteriores, o modo de avaliação e recuperação, as instalações necessárias, assim como equipamentos, recursos tecnológicos e bibliotecas, recursos humanos envolvidos no curso, e os critérios de certificação. Este plano é utilizado por todos os envolvidos no processo, a coordenação pedagógica e técnica, tutores, monitores e mediadores. Ele orienta todos os demais planos.

Outro documento norteador recebido do Departamento Nacional é o Plano de Ensino, onde está descrito a ordem de execução das unidades curriculares, a carga horária presencial e a distância que o curso terá, e os planos das situações de aprendizagem. Este documento é utilizado pela coordenação pedagógica e técnica e pelos tutores.

Através desses documentos, os tutores desenvolvem os demais documentos necessários, o plano de tutoria é um norteador da prática utilizada pelo professor/tutor durante cada UC (Unidade Curricular), nele se menciona o conteúdo a ser trabalhado, o objetivo do ensino, a metodologia que o tutor irá empregar para que se alcance esses objetivos, e o método de avaliação, como se desenvolverá a situação de aprendizagem aplicada. Essas chamadas Situações de aprendizagem, precisam ser um conjunto de ações que norteiam o desenvolvimento da prática docente.

Portanto, o plano de tutoria deve ser elaborado até 20 dias antes do início do curso, para a validação da equipe pedagógica e técnica, que tem até 10 dias antes no início do curso para realizar a validação. Este plano, tem que estar disponível na pasta do curso para acompanhamento das tarefas a serem desenvolvidas até a finalização do curso.

A partir deste, é elaborado pelo tutor o Plano de estudos do aluno, documento que situa o curso em todo o seu decorrer, deve ser postado para o aluno dentro do Ambiente virtual de aprendizagem. Nele contém informações de ambientação da sala virtual, período de realização de cada UC, as datas de entregas das atividades, os recursos que precisam para a realização da UC, e descrição da Situação de Aprendizagem - SAP a ser trabalhada, instruções de acessos a cada área que vai ser utilizada, qual o período que o aluno terá para estudar determinado conteúdo, se haverá momentos presenciais e as datas dos encontros. Deverá ser entregue para a validação pelo tutor até 20 dias antes do início do curso, é um documento utilizado pelo aluno, e postado na pasta do 
curso e no AVA - Ambiente Virtual de Aprendizagem.

Em seguida, é desenvolvido o plano de aulas presenciais, elaborado pelo tutor para nortear o professor do momento presencial na aplicação da aula. Contém os conteúdos a serem trabalhados no decorrer da aula, o objetivo da aula, as estratégias que deverão ser utilizadas para alcançar os objetivos, os recursos necessários para a sua realização, qual será o instrumento de avaliação do aluno, e a carga horária que a aula terá. Também é entregue para a validação até 20 dias antes do início do curso. E deverá ser postado no AVA até 15 dias antes do momento presencial.

Posteriormente, cria-se o Guia do aluno, documento de apresentação do curso para o aluno, onde se menciona, a carga horária do curso, o objetivo geral, assim como os objetivos específicos, os materiais de estudos, qual a metodologia de avaliação utilizada, apresentação da equipe envolvida na execução de seu curso, como se dá a certificação e algumas dicas de estudos.

\section{Apresentação e Discussão dos Resultados}

Por conseguinte, para que o curso ocorra é necessário a existência e validação de todos os documentos acima listados, Plano de Curso, Guia do aluno, Plano de ensino, Plano de tutoria, Plano de estudos do aluno, Situações de Aprendizagem, Planos de Aulas presenciais (nos cursos que possuem). É observado se os objetivos centrais selecionados estão inter-relacionados com o conteúdo, se as atividades e recursos de ensino estão de acordo com o plano de ensino, se o professor utilizou de diferentes estratégias para realizar o ensino do aluno, se há uma variedade de atividades e recursos planejados para as aulas, se o tempo de execução que o professor planejou está de acordo com que vai ser trabalhado, e por fim, se todos os planos estão condizentes uns com os outros.

Outrossim, partimos para a sala de aula virtual, a partir da validação do curso cada tutor responsável tem um prazo de até 10 dias para a parametrizar o ambiente virtual. Neste, os alunos são inseridos a partir de um cronograma dos cursos, onde é mencionado o período de realização de cada UC, decidido anteriormente pela equipe técnica.

Uma vez que, os alunos a distância estão inseridos no ambiente virtual, eles possuem um acompanhamento por várias pessoas envolvidas nesse processo, pelo tutor, que está para orientar, instigar, incentivar, e esclarecer dúvidas relacionadas a conteúdos, outra figura importante é do monitor, que está inserido para atender as demandas administrativas, dúvidas dos alunos a respeito de certificação, problemas de acessos a sala de aula, conferir o acesso dos alunos, e demais assuntos que mantém o bom funcionamento do curso. Além desses, possui o mediador, ele está inserido em determinados cursos para esclarecer dúvidas de navegação, realizar contato com aluno, por meio de ligações e mensagens, alertando prazos de entregas de atividades, e 
esclarecimento de critérios para certificação.

Para tudo existe a equipe pedagógica e técnica que auxiliam em todo processo, são realizadas reuniões semanais com todos os envolvidos para compartilhar atitudes inovadoras, análises de planos em conjunto e pensar planos de ações para eficácia do curso.

Após a conclusão de cada curso, é analisado pela coordenação pedagógica, os resultados obtidos, nos índices de concluintes, evadidos, reprovados em cada curso, na perspectiva de cada unidade curricular, cada a unidade ofertante, e no caso de evasão, em qual período do curso ela ocorreu em maior quantidade.

Deste modo, é apresentado aos tutores e demais envolvidos os resultados, para se pensar um planejamento de ações que visem a melhoria dos processos.

\footnotetext{
Planejar, então, remete a: querer mudar algo; acreditar na possibilidade de mudança da realidade; perceber a necessidade teórico-metodológica; vislumbrar a possibilidade de realizar aquela determinada ação. Para que a atividade de projetar seja carregada de sentido, é preciso, pois, que, a partir da disposição para realizar alguma mudança, o educador veja o planejamento como necessário (aquilo que se impõe, que deve ser, que não se pode dispensar) e possível (aquilo que não é, mas poderia ser, que é realizável).(VASCONCELLOS,2015)
}

\section{Considerações Finais}

De acordo com o crescimento e perspectiva atual de educação, e pensando em atender essa demanda da indústria e do aluno como sujeito, o NIEAD- Núcleo Integrado SESI/SENAI de Educação a Distância, realiza algumas inovações de aprendizagem, que se destacam na educação a distância. São elas promover a adequação dos conteúdos aos determinados públicos; promover o uso das várias tecnologias para a promoção da inovação; valoriza o perfil de cada aluno, sem seguir modelos; desenvolve várias habilidades durante os cursos, não só de habilidades técnicas; realiza processos de aprendizagem pelo significado, e não pelo conteúdo, adequar o conteúdo a realidade de cada aluno. Como exemplo, a utilização de redes sociais, games, entre outros; fortalecimento da autonomia e criatividade dos alunos através da metodologia SENAI; determinadas situações de Aprendizagem propostas em Grupo (as nossas Situações de Aprendizagem precisam ser dinâmicas, que incentivem a inovação e criatividade, integrando teoria e prática); inovação não apenas como inserção de tecnologias, mas sim a favor da introdução de tecnologias na formação dos arranjos e relações sociais; engajamento de Mobile em aplicativos (como nós já utilizamos, o SENAI APP, que o aluno consegue acessar o Ambiente Virtual de Aprendizagem do próprio celular e em qualquer horário e local. Livros SENAI (Estante Virtual) como ferramenta na substituição de livros impressos. O aplicativo de Realidade Aumentada (RA), onde permite que o aluno mesmo a distância consiga ter uma experiência virtual aumentada.

Em suma, o planejamento educacional na educação a distância ocorre na perspectiva 
de promover estratégias e métodos de ensinos atualizados com as demandas atuais que garantam a permanência do aluno e o aproveitamento dos cursos, em uma visão significativa do sujeito em sociedade, buscando sua formação humanística e integral.

\section{Referencial Bibliográfico}

ALVES, Lucineia. Educação a distância: conceitos e história no Brasil e no mundo.Disponível em : Acesso em: 18 jun. 2018.

BRASIL. Lei de Diretrizes e Bases da Educação Nacional - LDB Lei o 9394/96. Disponível em: Acesso em: 18 jun.2018.

FREIRE, Paulo; FAUNDEZ, Antonio. Por uma pedagogia da pergunta. Rio de Janeiro: Paz e Terra, 1985. p.49.

FREIRE, Paulo. CONSCIENTIZAÇÃO: Teoria e Prática da Libertação: Uma Introdução ao Pensamento de Paulo Freire. São Paulo: Cortez \& Moraes, 1979. Tradução de Kátia de Mello e silva; revisão técnica de Benedito Eliseu Leite Cintra.

LUCKESI, Cipriano Carlos. Planejamento e Avaliação na escola: articulação e necessária determinação ideológica. In: LUCKESI, Cipriano Carlos. Avaliação da aprendizagem escolar: estudos e proposições. 19. ed. São Paulo: Cortez, 2008. Cap. 6. p. 102-119.

PERASSO, Valeria. O que é a $4^{a}$ revolução industrial: e como ela deve afetar nossas vidas. 2016. Disponível em: <https://www.bbc.com/portuguese/geral-37658309>. Acesso em: 06 ago. 2018.

SERVIÇO NACIONAL DE APRENDIZAGEM INDUSTRIAL (Brasília). Departamento Nacional. Norteador da Prática Pedagógica: Formação com base em competências. Brasília: Senai/DN, 2006. 88 p.

VASCONCELLOS, Celso dos Santos. Projeto de Ensino-Aprendizagem e Projeto Político-Pedagógico: elementos metodológicos para elaboração e realização. 25. ed. São Paulo: Libertad Editora, 2015. 1 v. Cadernos Pedagógicos do Liberted

VYGOSTSKY, L. A formação social da mente. São Paulo: Martins Fontes, 1989.

ZITKOSKI, Jaime José. Paulo Freire \& a Educação. 2. ed. Belo Horizonte: Autêntica 
Editora, 2010. 96 p. 